\title{
Social Support and Depressive Symptoms: Exploring Stigma and Self-Efficacy in a Moderated Mediation Model
}

\section{Dong-Fang Wang}

Technical University of Munich

\section{Yue-Jiao Ma}

The Second Xiang-ya Hospital, Central South University

\section{Ya-Nan Zhou}

The Second Xiang-ya Hospital, Central South University

\section{Yue-Heng Liu}

The Second Xiang-ya Hospital, Central South University

\section{Yu-Zhu Hao}

The Second Xiang-ya Hospital, Central South University

\section{Jun-Hong Zhang}

The Second Xiang-ya Hospital, Central South University

\section{Tie-Qiao Liu ( $D$ 503044@csu.edu.cn )}

The Second Xiang-ya Hospital, Central South University

\section{Research Article}

Keywords: substance use disorder, stigma, perceived social support, self-efficacy, depressive symptoms, moderated mediation model

Posted Date: August 23rd, 2021

DOl: https://doi.org/10.21203/rs.3.rs-708422/v1

License: (1) (1) This work is licensed under a Creative Commons Attribution 4.0 International License. Read Full License

Version of Record: A version of this preprint was published at BMC Psychiatry on February 15th, 2022. See the published version at https://doi.org/10.1186/s12888-022-03740-6. 


\section{Abstract}

Background: Although some psychological processes, such as stigma and self-efficacy, affect the complicated relationship between social support and depressive symptoms, few studies explored a similar psychological mechanism among individuals with substance use disorders. Hence, this research investigates the mediating effects of stigma and the moderating effects of self-efficacy among the psychological mechanism that social support affects depressive symptoms.

Methods: The study included 1040 Chinese participants with substance abuse disorders (SUDs) and completed a series of self-report questionnaires. R software was used to organize and clean up data sets and analyze mediation and moderation effects.

Results: The result showed that stigma had a partial mediating effect on depressive symptoms, while self-efficacy moderated this relationship. More specifically, less social support increased depression symptoms by bringing about higher stigma. Besides, subjects with higher self-efficacy are less susceptible to stigma and therefore have mild depressive symptoms. Furthermore, clinical and theoretical implications are discussed in our study.

Conclusions: Chinese SUDs patients' depressive symptoms were indirectly affected by perceived social support via stigma and less affected by stigma with improved self-efficacy. The theoretical and practical implications of these results are discussed.

\section{Introduction}

The latest report showed that 2.14 million people have drug use problems in china [1]. According to the world drug report, nearly 271 million people have experienced drug use in 2018, and 35 million individuals suffer from SUDs [2]. Worse, SUDs commonly co-occurs with depressive symptoms [3]. Depressive symptoms among people with SUDs can lead to more severe dysfunction, poor treatment results, higher morbidity, mortality, and more treatment costs [4-9].

Social support, one of the essential factors that can affect depressive symptoms of people with SUDs, is a concept that one feels cared for by others and has a reliable social network, such as family members, friends, and significant others [10]. It is reported that perceived social support positively relates to psychological well-being [11-13], and protects against depressive symptoms and psychological distress [14-16]. For example, family support, such as administering medication, cooking meals, and emotional support, could help patients recover [17]. Conversely, lacking social support or suffering from social isolation will adversely affect mental health [18].

In summary, good social support can help reduce depressive symptoms among patients with SUDs. However, the study on how and when social support affects depressive symptoms in patients with SUDs remains unclear. Therefore, it is necessary to explore the relationship between perceived social support and depressive symptoms. 


\subsection{The Mediating Role of stigma between perceived social support and depressive symptoms}

Stigma is a mark of shame and disapproval resulting in an individual being rejected, discriminated against, and excluded from society [19]. Individuals with SUDs are more likely to be blamed by others [20] and think of themselves as inferior [21]. The public often discriminates against SUDs patients [22], regarding them as violent and dangerous [23]. Even worse, doctors as the primary helpers also held negative attitudes toward SUDs patients. As a consequence, it would negatively affect treatment efficacy [24]. Therefore, they are more likely to experience severe social isolation in personal life or workplace and be treated differently in national policies $[22,25]$.

Furthermore, the stigmatization of SUDs patients may cause emotional, physical, cognitive stress responses [26] 囚even mental disorders - depression and anxiety [27-32]. For example, a study about alcohol addiction showed that the feeling of hurt resulted from stigma would easily convert into depressive symptoms, such as unworthiness or embarrassment [33]. A similar conclusion has also been proved in patients with opioid use disorder [34].

Previous studies have indicated that social support and internalized stigma can predict mental illness, such as depression, among HIV patients $[35,36]$. For example, a poor social network has been shown to increase internalized stigma in schizophrenia [37]. Conversely, Poor interpersonal relationships may increase stigma [37, 38]. Although studies have shown that perceived social support can mediate stigma and depression[39], the relationship between stigma and perceived social support might also work in the other way, from social support to stigma. For instance, Birtel et al. reported the mediation effect of internalized stigma between the perceived social support and depressive symptoms with a small size of 64 SUDs individuals [40], which indicated that if one with SUDs can feel more supported by others, such as family remembers or friends, they may lower be internalizing the negative public views to them and then reduce internalized stigma to reduce depressive symptoms.

\subsection{The Moderating Role of Self-efficacy between stigma and depressive symptoms}

Self-efficacy is a faith that an individual can successfully execute behaviors to achieve desired aims [41]. Self-efficacy could improve the ability to change substance use behaviors, such as drinking behavior [42, 43]. In addition, self-efficacy might contribute to cognitive and behavioral changes [44]. Although some studies have shown a correlation between self-efficacy and stigma in individuals with mental illness [45] and alcohol addiction [32], few studies have explored the relationship between stigma and self-efficacy in SUDs patients.

High self-efficacy is associated with positive outcomes, such as a low depressive symptom and increased well-being [46-48]. In addition, people with solid self-efficacy have the good emotional regulation ability. Hence, they are more likely to perceive satisfaction and experience more positive emotions $[49,50]$. In contrast, low self-efficacy is more likely to produce negative emotions, like depression, anxiety [51, 52]. Additionally, many studies have demonstrated that patients with depressive 
symptoms reported low self-efficacy [53-55]. Therefore, we speculate that self-efficacy may have a moderating effect on stigma and depression symptoms.

\subsection{The purpose of the study}

The present study explored how stigma and self-efficacy influence the relationship between social support and depressive symptoms among Chinese SUDs patients by establishing a structural equation model. The hypothetical model is shown in Figure 1, and the following hypothesis is proposed:

Hypothesis $1(\mathrm{H} 1)$ : stigma could mediate the relationship between perceived social support and depressive symptoms.

Hypothesis $2(\mathrm{H} 2)$ : self-efficacy could moderate the indirect association between stigma and depressive symptoms.

\section{Methods}

\subsection{Participants and procedure}

It is a descriptive case-control study conducted at two Compulsory Drug Rehabilitation Centers in Hunan province, China. Patients had to meet the diagnosis of substance use disorders (SUDs) according to the Diagnostic and Statistical Manual of Mental Disorders (DSM-5). The study was conducted from February 2020 until the end of December 2020. After signing the informed consent, subjects finished the relevant questionnaires. The investigation gained ethical approval from the second Xiang-Ya Hospital of Central South University (Application Number LYF2020109).

\subsection{Measures}

\section{Social-Demographics Questionnaire}

The research team developed the Social-Demographics Questionnaire in light of the literature. It consists of eight questions to collect information about the participants' socio-demographic characteristics, including age, job, gender, salary, marital status, education level, smoking and drinking, and substance use-related characteristics.

\section{The Substance Use Stigma Mechanisms Scale (SU-SMS)}

The Substance Use Stigma Mechanisms Scale was used to measure stigma mechanisms among patients with SUDs [56]. This study used the Chinese version of SU-SMS (SUSMS-C) [57], containing five factors and 18 items on a five-point Likert scale. The higher the score on the scale, the more severe the stigma suffered by the individual. The SUSMS-C has good reliability and validity in Chinese patients with substance use disorder, showing the internal consistency reliability is between $0.724-0.909$, the testretest reliability is 0.702 [57]. In the present research, Cronbach's alpha was 0.88 . 


\section{The multidimensional scale of perceived social support (MSPSS)}

In this study, we used the Chinese version of the Perceived Social Support Scale (MSPSS) to assess the level of social support [58], which contains a total of 12 items on a seven-point Likert scale. Cronbach's alpha of MSPSS was 0.89 in Chinese adolescents [58]. In the present research, Cronbach's alpha was 0.92 .

\section{The Centre for Epidemiologic Studies Depression Scale (CES-D).}

We assessed depressive symptoms with CES-D [59]. CES-D contains 20 items on a four-point Likert scale. The higher the total score, the more severe the depression. This Chinese version of the CES-D has satisfactory reliability and internal validity and has been widely used in the Chinese population [60]. In the present research, Cronbach's alpha was 0.87.

\section{The General Self Efficacy Scale (GSES)}

We used the General Self Efficacy Scale (GSES) [34], which contains ten items based on four responses, to assess self-efficacy. A lower score indicates a lower level of general self-efficacy. This scale has good reliability and validity in the Chinese population [61]. In the present research, Cronbach's alpha was 0.71.

\subsection{Statistical analyses}

We used R software (version 3.6.3) to organize and clean the dataset and generate the correlations. We used 'process [62] and the 'lavvan'packages [63], which allows us to analyze mediation and moderation effects at the same time [64]. We tested a moderated mediation model, in which social support served as the independent variable $(X)$, negative affect stigma served as the mediating variable $(W)$, depression served as the dependent variable (outcome, Y). Self-efficacy served as the moderator variable (V). Additionally, we also performed a simple slope computation of the moderation model to test the significance of the moderation slopes. To make the results more robust, we conduct the bootstrapping procedure $[65,66]$. In this research, we adopt 1000 Bootstrap samples.

\section{Results}

\subsection{Demography}

One thousand and forty SUDs (204 females, 836 males) aged 16 and 65 years (Mean = 35.38, SD = 8.49) took part in this research. In this study, 785 participants $(75.48 \%)$ mainly used methamphetamine, following heroin users were 171 (16.44\%), and ketamine users were 62 patients (5.96\%). (Table 1) 
Table 1

Descriptive statistics of socio-demographic. $(N=1040)$

\begin{tabular}{|c|c|c|}
\hline & & Total N (\%) \\
\hline \multicolumn{3}{|l|}{ Gender } \\
\hline & male & $836(80.4 \%)$ \\
\hline & female & $204(19.6 \%)$ \\
\hline \multicolumn{3}{|l|}{ Occupation } \\
\hline & Unemployment & $143(13.75 \%)$ \\
\hline & Employment & $897(86.25 \%)$ \\
\hline \multicolumn{3}{|l|}{ Marry } \\
\hline & unmarried & $630(60.58 \%)$ \\
\hline & married & $410(39.42 \%)$ \\
\hline \multicolumn{3}{|l|}{ Income (CNY/Month) } \\
\hline & $<2000$ & $153(14.7 \%)$ \\
\hline & $2000 \sim 5000$ & $365(35.1 \%)$ \\
\hline & $5000 \sim 10000$ & $336(32.3 \%)$ \\
\hline & $>10000$ & $186(17.9 \%)$ \\
\hline \multicolumn{3}{|l|}{ Smoking } \\
\hline & Y & $987(94.9 \%)$ \\
\hline & $\mathrm{N}$ & $53(5.1 \%)$ \\
\hline \multicolumn{3}{|l|}{ Drinking } \\
\hline & Y & $536(51.5 \%)$ \\
\hline & $\mathrm{N}$ & $504(48.5 \%)$ \\
\hline \multicolumn{3}{|l|}{ Drug kind } \\
\hline & Methamphetamine & $785(75.48 \%)$ \\
\hline & Heroin & $171(16.44 \%)$ \\
\hline & ketamine & $62(5.96 \%)$ \\
\hline & Others & $22(2.12 \%)$ \\
\hline
\end{tabular}


The score of CES-D positively linked with that of SU-SMS (Pearson correlation $=0.49, \mathrm{P}<0.01$ ), while negatively correlated with that of GSES (Pearson correlation $=-0.33, p<0.01$ ), and MSPSS (Pearson correlation $=-0.33, P<0.01)$. Further analysis of the data revealed that there was a significant negative correlation between SU-SMS and GSES (Pearson correlation $=-0.16, p<0.001$ ), as well as MSPSS (Pearson correlation $=-0.27, P<0.01)$. Additionally, MSPSS positively correlated with GSES (Pearson correlation $=0.29, \mathrm{P}<0.01)($ Table 2$)$.

Table 2

Means, standard deviations and correlations for the variables.

\begin{tabular}{|c|c|c|c|c|c|}
\hline & Means (SD) & GSES & CES-D & SU-SMS & MSPSS \\
\hline GSES & $24.02(6.73)$ & 1 & & & \\
\hline CES-D & $20.92(9.22)$ & $-0.33^{* \star}$ & 1 & & \\
\hline SU-SMS & $45.18(11.38)$ & $-0.16^{\star \star}$ & $0.49 * *$ & 1 & \\
\hline MSPSS & $58.75(12.72)$ & $.029 * \star$ & $-0.33^{\star \star}$ & -0.27 ** & 1 \\
\hline
\end{tabular}

The result of linear regression analysis with depression as the dependent variable and clinical data (MSPSS, SU-SMS, GSES, GSES: MSPSS) as independent variables showed that MSPSS-C $(\beta=-0.16, p<$ $0.01)$, SU-SMS $(\beta=0.84, p<0.01)$, the interaction of GSES and MSPSS-C $(\beta=-0.60, p=0.01)$ were independent variables to predict CES-D, and the total explanatory quantity of the three variables was $35 \%$ (Table 3).

Table 3

Moderated mediation testing results.

\begin{tabular}{|c|c|c|c|c|c|c|c|c|}
\hline Outcome & Predictors & Path & b & SE & z-value & $\mathrm{P}(>|z|)$ & LLCl & ULCI \\
\hline \multicolumn{9}{|l|}{ SU-SMS } \\
\hline & MSPSS & (a) & -0.24 & 0.032 & -7.56 & $<0.01$ & -0.24 & -0.27 \\
\hline \multicolumn{9}{|l|}{ CES-D } \\
\hline & MSPSS & (c) & -0.11 & 0.02 & -5.32 & $<0.01$ & -0.12 & -0.11 \\
\hline & SU-SMS & (b1) & 0.68 & 0.07 & 9.36 & $<0.01$ & 0.68 & 0.61 \\
\hline & GSES & (b2) & 0.36 & 0.13 & 2.84 & $<0.01$ & 0.36 & 0.19 \\
\hline & SU-SMS : GSES & (b3) & -0.02 & 0.01 & -5.12 & $<0.01$ & -0.02 & -0.44 \\
\hline \multicolumn{9}{|c|}{$\begin{array}{l}\text { Note: SU-SMS: Substance Use Stigma Mechanisms Scale; MSPSS: the multidimensional scale of } \\
\text { perceived social support; CES-D: Centre for Epidemiologic Studies Depression Scale; GSES: General } \\
\text { Self Efficacy Scale. }\end{array}$} \\
\hline
\end{tabular}




\subsection{The Moderated Mediation Model}

To confirm whether stigma plays a mediating role in the relationship between perceived social support and depressive symptoms and whether this mediation was moderated by self-efficacy, a moderated mediation model was constructed.

The unstandardized regression coefficients of each path of the model were shown in Fig. 2.

The direct effect between perceived social support and depressive symptoms was significant (path c': $\beta=$ $-0.11, p<0.01,95 \% \mathrm{Cl}[0.08,0.16])$. In the mediation analysis, perceived social support negatively predicted stigma (path a': $\beta=-0.24, p<0.01,95 \% \mathrm{Cl}[-0.27,-0.24]$ )., and stigma positively predicted depressive symptoms (path b1': $\beta=0.68, p<0.01,95 \% \mathrm{Cl}[0.61,0.68]$ ). Hypothesis 1 was supported. (Table 3 )

The interaction effect between stigma and self-efficacy on depressive symptoms was significant (path b3: $\beta=-0.02, p=0.01,95 \% \mathrm{Cl}[-0.02,-0.44])$. Through the moderating effect of self-efficacy on stigma, the analysis results of the indirect influence of social support on depressive symptoms are as follows: the indirect effect was significant for both low self-efficacy $(\beta=-0.10$, SE $=0.0295 \% \mathrm{Cl}-0.13,-0.07)$, and high self-efficacy $(\beta=-0.05 \mathrm{SE}=0.01,95 \% \mathrm{Cl}-0.07,-0.03$ ) (Table 4). Figure 3 shows the moderation effect of self-efficacy on the relationship between stigma and depressive symptoms.

Table 4

Conditional indirect effect of perceived social support on depressive symptoms through stigma by self-efficacy.

\begin{tabular}{|lllll|}
\hline Self-efficacy & Effect & BootSE & BootLLCI & BootULCI \\
\hline Low self-efficacy & -0.10 & 0.02 & -0.13 & -0.07 \\
\hline Moderate self-efficacy & -0.08 & 0.01 & -0.11 & -0.06 \\
\hline High self-efficacy & -0.05 & 0.01 & -0.07 & -0.03 \\
\hline
\end{tabular}

\section{Discussion}

The present study explored the mediator role of stigma between social support and depressive symptoms among SUDs patients by a moderated mediation model, which showed that stigma partially $(38.51 \%)$ mediated the relationship between perceived social support and depressive symptoms. More specifically, less social support increased depressive symptoms by bringing about higher stigma. We also found that self-efficacy significantly alleviated the effect of stigma on depressive symptoms, suggesting that SUDs patients with high self-efficacy are less affected by stigma.

An exciting finding indicated that the SUDs-related stigma mediates the relationship between perceived social support and depressive symptoms, which confirmed our $\mathrm{H} 1(\mathrm{H} 1)$-in line with previous studies, suggesting that a poor social network could induce severe internalized stigma in schizophrenics [37, 38]. It has been widely reported that social support can be used as a predictor of depressive symptoms and 
stigma $[14,15,35,67,68]$. A study in a population of women infected with Acquired immunodeficiency syndrome (AIDS) found that stigma could mediate the relationship between social support and depressive symptoms [69]. Similar results were also found in substance abuse patients [40]. Therefore, given that the above results indicate that a supportive environment, including equal acceptance of SUDs patients and providing necessary help and care, can help patients build self-esteem and alleviate depression.

On the contrary, a hostile environment can cause SUDs patients to believe that they are primarily responsible for the disease, therefore exacerbating the stigma. This finding highlights the importance of social support for SUDs patients. SUDs patients with reliable social support are accompanied by lower stigma, which can help reduce the mental stress associated with SUDs, such as depression symptoms. Our finding emphasized the necessity to provide more social support for SUDs patients and reduce their stigma. We also found that self-efficacy moderated the relationship between stigma and depressive symptoms, which supported former studies showing that stigma can lower self-efficacy among individuals with alcohol addiction [32]. However, the study results about internet addiction did not prove that self-efficacy could influence stigma [70]. This is inconsistent with our results. The discrepancy could come down to the different samples. We speculate that people with internet addiction would perceive less stigma from their family members and peers than patients with SUDs.

Individuals with a high sense of self-efficacy have strong beliefs to accomplish the goals. Therefore, they are rarely interfering with ed by the negative evaluation of others, such as stigma. The labeling theory proposed by Link et al. could help us further explain this result, suggesting that stigma affects mental health by destroying the evaluation dimension of self-, concept which is mainly related to self-efficacy [71]. Decreased self-efficacy has been shown to weaken personal empowerment, and reduced power can lead to a higher level of depression [72].

Additionally, Bandura. et al. put forward that self-efficacy relieves depressive symptoms in SUDs patients because depression may stem, in part, from conditions that induce a belief that they cannot overcome the difficulties [73]. Hence, Curran. et al. also explain why self-efficacy can be a strong predictor of abstinence [74]. Earlier studies have shown that self-efficacy can reduce the recurrence rate of substance use patients $[75,76]$. We speculate that this may be achieved by reducing depressive symptoms.

These findings emphasize that both stigma and social support should be considered when treating SUDs patients with depression. A prior clinical trial applied acceptance and commitment therapy to reduce the stigma on SUDs patients, and the results showed that decreasing the stigma could improve emotions, cognitions, and behaviors [77]. Psychotherapy research found a relatively enduring and robust effect of stigma on well-being, indicating that if therapists wish to maximize the well-being of the people they treat, they must pay more attention to addressing stigma [78]. The social support network is an essential factor that should be considered in reducing SUDs related stigma [37, 38], which can be subdivided into multiple dimensions according to the source (e.g., peers, family) and type (e.g., general support or specific support for abstinence [79]. For example, peers in mutual aid groups are the primary support source outside of the 
conventional treatment of alcohol addiction [80]. A clinical study explored the efficacy of 12-step group therapy in 121 patients diagnosed with SUDs and mental disorders showing that self-help groups help reduce mental health and the severity of drug abuse symptoms [81]. Another source of social support is family [82]. Family members, such as parents, play a crucial role in helping patients meet basic demands. Good family support could help patients reduce the impact of stigma [37, 38]. However, if the patient brings a high level of stress and tension, which overwhelming the family's ability to cope, it may lead to reduced family support [83]. Therefore, psychiatrists should pay more attention to increase social support and reduce the stigma of SUDs.

In addition to conventional interventions, doctors should also improve patients' self-efficacy, thereby reducing the adverse effects of stigma on patients and improving mental health. For example, some research has indicated that applying Zen or Tao can resist the urge to drink or take drugs by enhancing self-efficacy [84]. In addition, psychotherapy research, cognitive-behavioral stress management (CBSM) on self-efficacy and relapses into a form of SUDs, shows that CBSM training contributes positively to increasing self-efficacy and lowering the risks of relapse into once again showing SUDs symptoms [85]. A system review that contained 37 interventions on self-efficacy showed that physical activity interventions might be an excellent choice to enhance self-efficacy [86]. Therefore, when treating SUDs patients with high levels of stigma, clinicians can consider encouraging patients to do more regular physical exercises to improve self-efficacy, reducing the negative emotions of drug patients being affected by stigma.

We should not ignore some limitations in the present research. First of all, the study is a cross-sectional study that contains some weaknesses, such as the inability to measure the incidence, difficulty making causal inferences, and making a causal inference [87]. In addition, this study did not control the influence of other confounding variables, for example, whether participants are accompanied by other mental illnesses (e.g., schizophrenia, bipolar disorder, depression, etc.). Moreover, while the model fits patients with drug use disorder, it is unknown whether the result could be expended to other populations, such as alcohol addiction.

Despite these limitations, this study contains some strengths. First of all, this is the first study to explore social support mechanisms affecting depression in a large sample of SUDs patients in China. We also consider the moderating effect of self-efficacy in the mediation model, which was ignored in previous studies $[40,69]$. Second, our research established a mediation model and chose a more reliable statistic1000 bootstrapping, to get robust results. Third, this study also provides some advice for clinical psychiatrists to improve treatment effects.

\section{Conclusion}

The present study reported the partial mediating role of stigma in the relationship between perceived social support and depressive symptoms and moderated by self-efficacy among Chinese SUDs patients. The results indicated the critical role of stigma and self-efficacy in treating SUDs patients with depressive symptoms. 


\section{Abbreviations}

Substance Use Stigma Mechanisms Scale (SU-SMS); the multidimensional scale of perceived social support (MSPSS); Centre for Epidemiologic Studies Depression Scale (CES-D); General Self Efficacy Scale (GSES); Substance abuse disorders (SUDs); cognitive-behavioral stress management (CBSM)

\section{Declarations}

Ethics approval and consent to participate: The investigation gained ethical approval from the second Xiang-Ya Hospital of Central South University (Application Number LYF2020109). All subjects signed an informed consent to participate in this study, which was carried out in accordance with the Helsinki Declaration.

Consent for publication: This study has obtained consent to publish from the participants to report individual patient data.

Availability of data and materials: The datasets used and/or analyzed during the current study are available from the corresponding author on reasonable requests.

Competing interests: No conflict of interest was disclosed for each author.

Funding: This work was supported by grants from the National Key R\&D Program of China (2017YFC1310400), the National Natural Science Foundation of China (81371465 and 81671324) and Funding Research Founds for the Central South University (2019zzts908). This research did not receive any specific grant from funding agencies in the public, commercial, or not-for-profit sectors.

Contributions: DF, YJ, YN, YH, YZ, JH, TQ. Data collection: YJ, YN, YH, YZ, JH. Analysis and interpretation of data: DF. Drafting of the manuscript: DF, YJ. Editing: DF, YJ, YN. Critical revision of the manuscript: TQ. All authors have read and approved the manuscript.

Acknowledgements: We sincerely thank all those have contributed to this article.

Authors' information: Not applicable.

\section{References}

1. Committee CNNC: China National Narcotics Control Committee. 2019 China Drug Situation Report. http://wwwgovcn/xinwen/2020-06/28/content_5522443htm 2019.

2. UNODC: World Drug Report 2019: stimulants, Booklet 4. In.: United Nations publication New York (NY); 2019.

3. Grant BF, Saha TD, Ruan WJ, Goldstein RB, Chou SP, Jung J, Zhang H, Smith SM, Pickering RP, Huang B: Epidemiology of DSM-5 drug use disorder: results from the National Epidemiologic Survey on Alcohol and Related Conditions-III. JAMA psychiatry 2016, 73(1):39-47. 
4. Blanco C, Alegría AA, Liu S-M, Secades-Villa R, Sugaya L, Davies C, Nunes EV: Differences among major depressive disorder with and without co-occurring substance use disorders and substanceinduced depressive disorder: results from the National Epidemiologic Survey on Alcohol and Related Conditions. Journal of Clinical Psychiatry 2012, 73(6):865-873.

5. Mojtabai R, Chen L-Y, Kaufmann CN, Crum RM: Comparing barriers to mental health treatment and substance use disorder treatment among individuals with comorbid major depression and substance use disorders. Journal of substance abuse treatment 2014, 46(2):268-273.

6. Statistics ABO: National survey of mental health and wellbeing: summary of results. Canberra, Australian Bureau of Statistics 2007.

7. Degenhardt L, Hall W, Lynskey M: Alcohol, cannabis and tobacco use among Australians: a comparison of their associations with other drug use and use disorders, affective and anxiety disorders, and psychosis. Addiction 2001, 96(11):1603-1614.

8. Drugs EMCf, Addiction D: Co-morbid substance use and mental disorders in Europe: A review of the data. In.: Publications Office of the European Union Luxembourg, Belgium; 2013.

9. Peles E, Schreiber S, Naumovsky Y, Adelson M: Depression in methadone maintenance treatment patients: rate and risk factors. Journal of affective disorders 2007, 99(1-3):213-220.

10. Taylor SE: Social support: A review. 2011.

11. Chu PS, Saucier DA, Hafner E: Meta-analysis of the relationships between social support and wellbeing in children and adolescents. Journal of social and clinical psychology 2010, 29(6):624-645.

12. Duko B, Gebeyehu A, Ayano G: Prevalence and correlates of depression and anxiety among patients with tuberculosis at WolaitaSodo University Hospital and Sodo Health Center, WolaitaSodo, South Ethiopia, Cross sectional study. BMC psychiatry 2015, 15(1):214.

13. Shapiro-Mendoza CK: Commentary: Mediation and moderation analyses: a novel approach to exploring the complex pathways between maternal medical conditions, preterm birth and associated newborn morbidity risk. International journal of epidemiology 2014, 43(3):815-817.

14. Archibald PC, Dobson Sydnor K, Daniels K, Bronner Y: Explaining African-Americans' depressive symptoms: A stress-distress and coping perspective. Journal of health psychology 2013, 18(3):321331.

15. Chatters LM, Taylor RJ, Woodward AT, Nicklett EJ: Social support from church and family members and depressive symptoms among older African Americans. The American Journal of Geriatric Psychiatry 2015, 23(6):559-567.

16. Sheffler J, Sachs-Ericsson N: Racial differences in the effect of stress on health and the moderating role of perceived social support. Journal of Aging and Health 2016, 28(8):1362-1381.

17. Jordan MR, La H, Nguyen HD, Sheehan H, Lien TTM, Duong D, Hellinger J, Wanke C, Tang AM: Correlates of HIV-1 viral suppression in a cohort of HIV-positive drug users receiving antiretroviral therapy in Hanoi, Vietnam. International journal of STD \& AIDS 2009, 20(6):418-422.

18. de Cuevas RMA, Al-Sonboli N, Al-Aghbari N, Yassin MA, Cuevas LE, Theobald SJ: Barriers to Completing TB Diagnosis in Yemen: Services Should Respond to Patients' Needs. PloS one 2014, 
9(9).

19. Weiss MG, Ramakrishna J: Stigma interventions and research for international health. The Lancet 2006, 367(9509):536-538.

20. Schomerus G, Lucht M, Holzinger A, Matschinger H, Carta MG, Angermeyer MC: The stigma of alcohol dependence compared with other mental disorders: a review of population studies. Alcohol and alcoholism 2011, 46(2):105-112.

21. Gilbert P: The relationship of shame, social anxiety and depression: The role of the evaluation of social rank. Clinical Psychology \& Psychotherapy: An International Journal of Theory \& Practice 2000, 7(3):174-189.

22. Barry CL, McGinty EE, Pescosolido BA, Goldman HH: Stigma, discrimination, treatment effectiveness, and policy: public views about drug addiction and mental illness. Psychiatric Services 2014, 65(10):1269-1272.

23. Pescosolido BA, Monahan J, Link BG, Stueve A, Kikuzawa S: The public's view of the competence, dangerousness, and need for legal coercion of persons with mental health problems. American journal of public health 1999, 89(9):1339-1345.

24. Van Boekel LC, Brouwers EP, Van Weeghel J, Garretsen HF: Stigma among health professionals towards patients with substance use disorders and its consequences for healthcare delivery: systematic review. Drug and alcohol dependence 2013, 131(1-2):23-35.

25. Parcesepe AM, Cabassa LJ: Public stigma of mental illness in the United States: a systematic literature review. Administration and Policy in Mental Health and Mental Health Services Research 2013, 40(5):384-399.

26. Blascovich J, Mendes WB, Hunter SB, Lickel B, Kowai-Bell N: Perceiver threat in social interactions with stigmatized others. Journal of personality and social psychology 2001, 80(2):253.

27. Birchwood M, Meaden A, Trower P, Gilbert P, Plaistow J: The power and omnipotence of voices: subordination and entrapment by voices and significant others. Psychological medicine 2000, 30(2):337-344.

28. O'Brien LT, Major B: System-justifying beliefs and psychological well-being: The roles of group status and identity. Personality and Social Psychology Bulletin 2005, 31(12):1718-1729.

29. Pascoe EA, Smart Richman L: Perceived discrimination and health: a meta-analytic review. Psychological bulletin 2009, 135(4):531.

30. Williams DR, Mohammed SA: Discrimination and racial disparities in health: evidence and needed research. Journal of behavioral medicine 2009, 32(1):20-47.

31. Beatty DL, Hall MH, Kamarck TA, Buysse DJ, Owens JF, Reis SE, Mezick EJ, Strollo PJ, Matthews KA: Unfair treatment is associated with poor sleep in African American and Caucasian adults: Pittsburgh SleepSCORE project. Health Psychology 2011, 30(3):351.

32. Schomerus G, Corrigan PW, Klauer T, Kuwert P, Freyberger HJ, Lucht M: Self-stigma in alcohol dependence: consequences for drinking-refusal self-efficacy. Drug and alcohol dependence 2011, 114(1):12-17. 
33. Heeren T, Edwards EM, Dennis JM, Rodkin S, Hingson RW, Rosenbloom DL: A comparison of results from an alcohol survey of a prerecruited Internet panel and the National Epidemiologic Survey on Alcohol and Related Conditions. Alcoholism: Clinical and Experimental Research 2008, 32(2):222229.

34. Akdağ EM, Kotan VO, Kose S, Tıkır B, Aydemir MÇ, Okay IT, Göka E, Özkaya G: The relationship between internalized stigma and treatment motivation, perceived social support, depression and anxiety levels in opioid use disorder. Psychiatry and Clinical Psychopharmacology 2018, 28(4):394401.

35. Simbayi LC, Kalichman S, Strebel A, Cloete A, Henda N, Mqeketo A: Internalized stigma, discrimination, and depression among men and women living with HIV/AIDS in Cape Town, South Africa. Social science \& medicine 2007, 64(9):1823-1831.

36. Li L, Lee S-J, Thammawijaya P, Jiraphongsa C, Rotheram-Borus MJ: Stigma, social support, and depression among people living with HIV in Thailand. AIDS care 2009, 21(8):1007-1013.

37. Sibitz I, Amering M, Unger A, Seyringer M, Bachmann A, Schrank B, Benesch T, Schulze B, Woppmann $A$ : The impact of the social network, stigma and empowerment on the quality of life in patients with schizophrenia. European psychiatry 2011, 26(1):28-33.

38. Mueller B, Nordt C, Lauber C, Rueesch P, Meyer PC, Roessler W: Social support modifies perceived stigmatization in the first years of mental illness: a longitudinal approach. Social Science \& Medicine 2006, 62(1):39-49.

39. Mickelson KD: Perceived stigma, social support, and depression. Personality and Social Psychology Bulletin 2001, 27(8):1046-1056.

40. Birtel MD, Wood L, Kempa NJ: Stigma and social support in substance abuse: Implications for mental health and well-being. Psychiatry Research 2017, 252:1-8.

41. Bandura A: Self-efficacy: toward a unifying theory of behavioral change. Psychological review 1977, 84(2):191.

42. Annis HM: A relapse prevention model for treatment of alcoholics. In: Treating addictive behaviors. edn.: Springer; 1986: 407-433.

43. Greenfield SF, Hufford MR, Vagge LM, Muenz LR, Costello ME, Weiss RD: The relationship of selfefficacy expectancies to relapse among alcohol dependent men and women: a prospective study. Journal of Studies on Alcohol 2000, 61(2):345-351.

44. Almeida RMMd, Flores ACS, Scheffer M: Suicidal ideation, problem solving, expression of anger and impulsiveness in dependents on psychoactive substances. Psicologia: Reflexão e Crítica 2013, 26(1):1-9.

45. Corrigan PW, Watson AC, Barr L: The self-stigma of mental illness: Implications for self-esteem and self-efficacy. Journal of social and clinical psychology 2006, 25(8):875-884.

46. Geiger KA: Understanding hope and self-efficacy in predicting symptoms of depression. 2012.

47. Chang Y, WANG PC, LI HH, LIU YC: Relations among depression, self-efficacy and optimism in a sample of nurses in Taiwan. Journal of nursing management 2011, 19(6):769-776. 
48. Asghari F, Saadat S, Atefi Karajvandani S, Janalizadeh Kokaneh S: The relationship between academic self-efficacy and psychological well-being, family cohesion, and spiritual health among students of Kharazmi University. Iranian Journal of Medical Education 2014, 14(7):581-593.

49. Caprara GV, Steca P, Gerbino M, Paciello M, Vecchio GM: Looking for adolescents' well-being: Selfefficacy beliefs as determinants of positive thinking and happiness. Epidemiology and Psychiatric Sciences 2006, 15(1):30-43.

50. Cheung S-K, Sun SY: Effects of self-efficacy and social support on the mental health conditions of mutual-aid organization members. Social Behavior and Personality: an international journal 2000, 28(5):413-422.

51. Muris P, Meesters C, Pierik A, de Kock B: Good for the self: Self-compassion and other self-related constructs in relation to symptoms of anxiety and depression in non-clinical youths. Journal of child and family studies 2016, 25(2):607-617.

52. Sinnakaruppan I, Macdonald K, McCafferty A, Mattison P: An exploration of the relationship between perception of control, physical disability, optimism, self-efficacy and hopelessness in multiple sclerosis. International journal of rehabilitation research 2010, 33(1):26-33.

53. Beck JG, Novy DM, Diefenbach GJ, Stanley MA, Averill PM, Swann AC: Differentiating anxiety and depression in older adults with generalized anxiety disorder. Psychological Assessment 2003, 15(2):184.

54. Blazer DG: Self-efficacy and depression in late life: a primary prevention proposal. Aging \& mental health 2002, 6(4):315-324.

55. Wardle J, Steptoe A, Guliš G, Sartory G, Sêk H, Todorova I, Vögele C, Ziarko M: Depression, perceived control, and life satisfaction in university students from Central-Eastern and Western Europe. International journal of behavioral medicine 2004, 11(1):27-36.

56. Smith LR, Earnshaw VA, Copenhaver MM, Cunningham CO: Substance use stigma: Reliability and validity of a theory-based scale for substance-using populations. Drug and alcohol dependence 2016, 162:34-43.

57. Yuejiao M, Dongfang W: 『eliability and validity of Chinese version of the Substance Use Stigma Mechanisms Scale. Chin J Drug Depend 2018, 27(5):339-343.

58. Chou K-L: Assessing Chinese adolescents' social support: the multidimensional scale of perceived social support. Personality and individual differences 2000, 28(2):299-307.

59. BERKMAN LF, BERKMAN CS, KASL S, FREEMAN DH, JR., LEO L, OSTFELD AM, CORNONI-HUNTLEY J, BRODY JA: DEPRESSIVE SYMPTOMS IN RELATION TO PHYSICAL HEALTH AND FUNCTIONING IN THE ELDERLY. American Journal of Epidemiology 1986, 124(3):372-388.

60. Wang Y, Yao L, Liu L, Yang X, Wu H, Wang J, Wang L: The mediating role of self-efficacy in the relationship between Big five personality and depressive symptoms among Chinese unemployed population: a cross-sectional study. BMC psychiatry 2014, 14(1):61.

61. Wang Z-Y, Liu L, Shi M, Wang L: Exploring correlations between positive psychological resources and symptoms of psychological distress among hematological cancer patients: a cross-sectional study. 
Psychology, health \& medicine 2016, 21(5):571-582.

62. White M: processr: R Implementation of the PROCESS Macro. R package version 00090002019.

63. Hox J, Bechger T: An introduction to structural equation modeling. Family Science Rewiew, 11, 354373. In.; 1998.

64. Hayes AF: Introduction to mediation, moderation, and conditional process analysis: A regressionbased approach: Guilford publications; 2017.

65. Byrne BM: Structural equation modeling with AMOS: basic concepts, applications, and programming (multivariate applications series). New York: Taylor \& Francis Group 2010, 396:7384.

66. Hayes AF, Preacher KJ: Quantifying and testing indirect effects in simple mediation models when the constituent paths are nonlinear. Multivariate behavioral research 2010, 45(4):627-660.

67. Beals KP, Peplau LA, Gable SL: Stigma management and well-being: The role of perceived social support, emotional processing, and suppression. Personality and Social Psychology Bulletin 2009, 35(7):867-879.

68. Ahern J, Stuber J, Galea S: Stigma, discrimination and the health of illicit drug users. Drug and alcohol dependence 2007, 88(2-3):188-196.

69. Vyavaharkar M, Moneyham L, Corwin S, Saunders R, Annang L, Tavakoli A: Relationships between stigma, social support, and depression in HIV-infected African American women living in the rural Southeastern United States. Journal of the Association of Nurses in AIDS Care 2010, 21(2):144-152.

70. Craparo G, Messina R, Severino S, Fasciano S, Cannella V, Gori A, Cacioppo M, Baiocco R: The relationships between self-efficacy, internet addiction and shame. Indian journal of psychological medicine 2014, 36(3):304.

71. Link BG, Phelan JC, Bresnahan M, Stueve A, Pescosolido BA: Public conceptions of mental illness: labels, causes, dangerousness, and social distance. American journal of public health 1999 , 89(9):1328-1333.

72. Vauth R, Kleim B, Wirtz M, Corrigan PW: Self-efficacy and empowerment as outcomes of selfstigmatizing and coping in schizophrenia. Psychiatry research 2007, 150(1):71-80.

73. Bandura A: Self-efficacy mechanism in human agency. American psychologist 1982, 37(2):122.

74. Curran G, Booth B, Kirchner J, Deneke D: Recognition and management of depression in a substance use disorder treatment population. The American journal of drug and alcohol abuse 2007, 33(4):563569.

75. Coon GM, Pena D, Illich PA: Self-efficacy and substance abuse: assessment using a brief phone interview. Journal of Substance Abuse Treatment 1998, 15(5):385-391.

76. Dolan SL, Martin RA, Rohsenow DJ: Self-efficacy for cocaine abstinence: Pretreatment correlates and relationship to outcomes. Addictive behaviors 2008, 33(5):675-688.

77. Luoma JB, Kohlenberg BS, Hayes SC, Bunting K, Rye AK: Reducing self-stigma in substance abuse through acceptance and commitment therapy: Model, manual development, and pilot outcomes. Addiction Research \& Theory 2008, 16(2):149-165. 
78. Link BG, Struening EL, Rahav M, Phelan JC, Nuttbrock L: On stigma and its consequences: evidence from a longitudinal study of men with dual diagnoses of mental illness and substance abuse. Journal of health and social behavior 1997:177-190.

79. Groh DR, Jason LA, Davis MI, Olson BD, Ferrari JR: Friends, family, and alcohol abuse: An examination of general and alcohol-specific social support. American Journal on Addictions 2007, 16(1):49-55.

80. Donovan DM, Anton RF, Miller WR, Longabaugh R, Hosking JD, Youngblood M, Group CSR: Combined pharmacotherapies and behavioral interventions for alcohol dependence (The COMBINE Study): examination of posttreatment drinking outcomes. Journal of Studies on Alcohol and Drugs 2008, 69(1):5-13.

81. Bogenschutz MP, Rice SL, Tonigan JS, Vogel HS, Nowinski J, Hume D, Arenella PB: 12-step facilitation for the dually diagnosed: A randomized clinical trial. Journal of substance abuse treatment 2014, 46(4):403-411.

82. Drake RE, Luciano AE, Mueser KT, Covell NH, Essock SM, Xie H, McHugo GJ: Longitudinal course of clients with co-occurring schizophrenia-spectrum and substance use disorders in urban mental health centers: a 7-year prospective study. Schizophrenia bulletin 2016, 42(1):202-211.

83. Mueser KT, Gingerich S: Treatment of co-occurring psychotic and substance use disorders. Social Work in Public Health 2013, 28(3-4):424-439.

84. Witkiewitz K, Marlatt GA: Relapse prevention for alcohol and drug problems: that was Zen, this is Tao. American psychologist 2004, 59(4):224.

85. Solati K, Hasanpour-Dehkordi A: Effectiveness of cognitive-behavioural stress management on selfefficacy and risk of relapse into symptoms of substance use disorders. Addiction is a treatable disease 2017.

86. Ashford S, Edmunds J, French DP: What is the best way to change self-efficacy to promote lifestyle and recreational physical activity? A systematic review with meta-analysis. British journal of health psychology 2010, 15(2):265-288.

87. Wang $X$, Cheng Z: Cross-sectional studies: strengths, weaknesses, and recommendations. Chest 2020, 158(1):S65-S71.

\section{Figures}




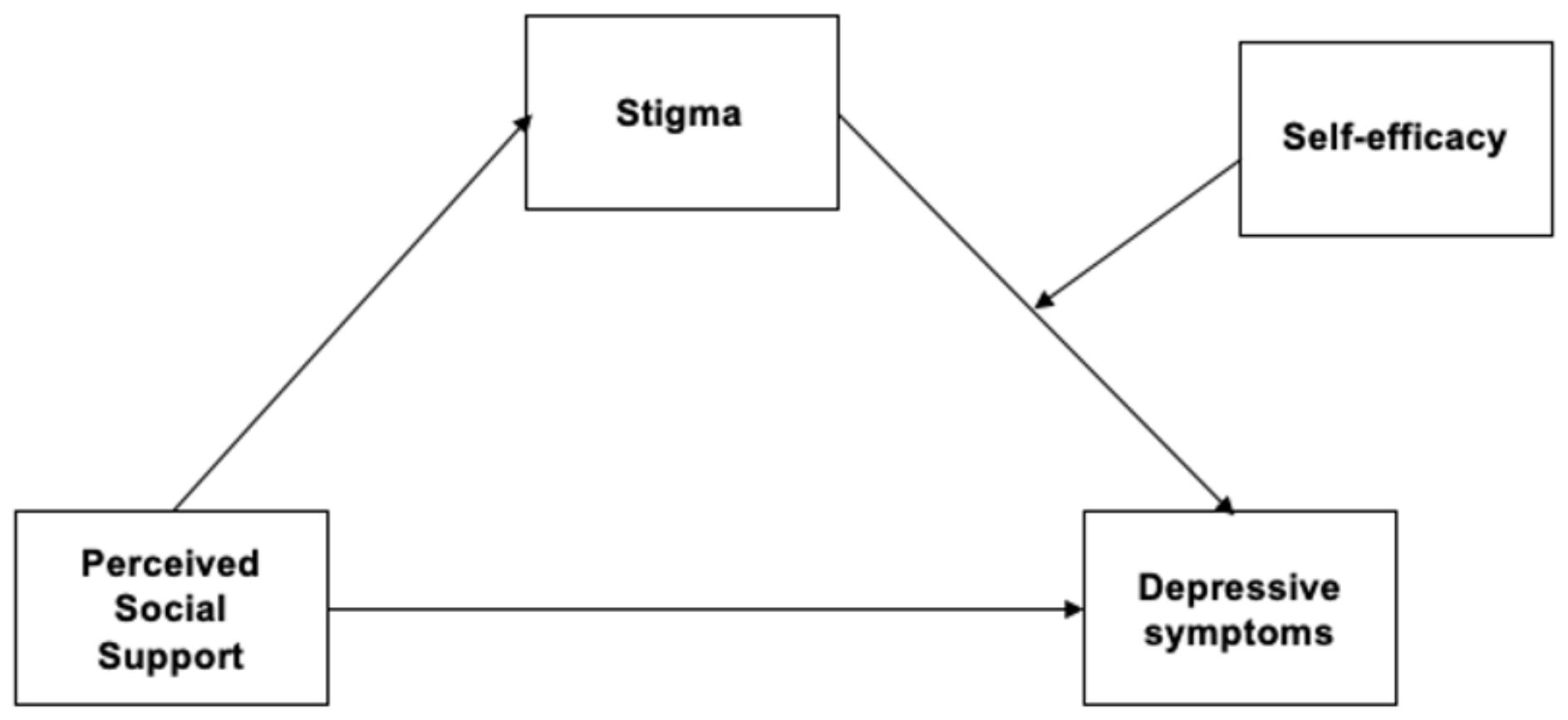

Figure 1

Conceptual framework of the current study.

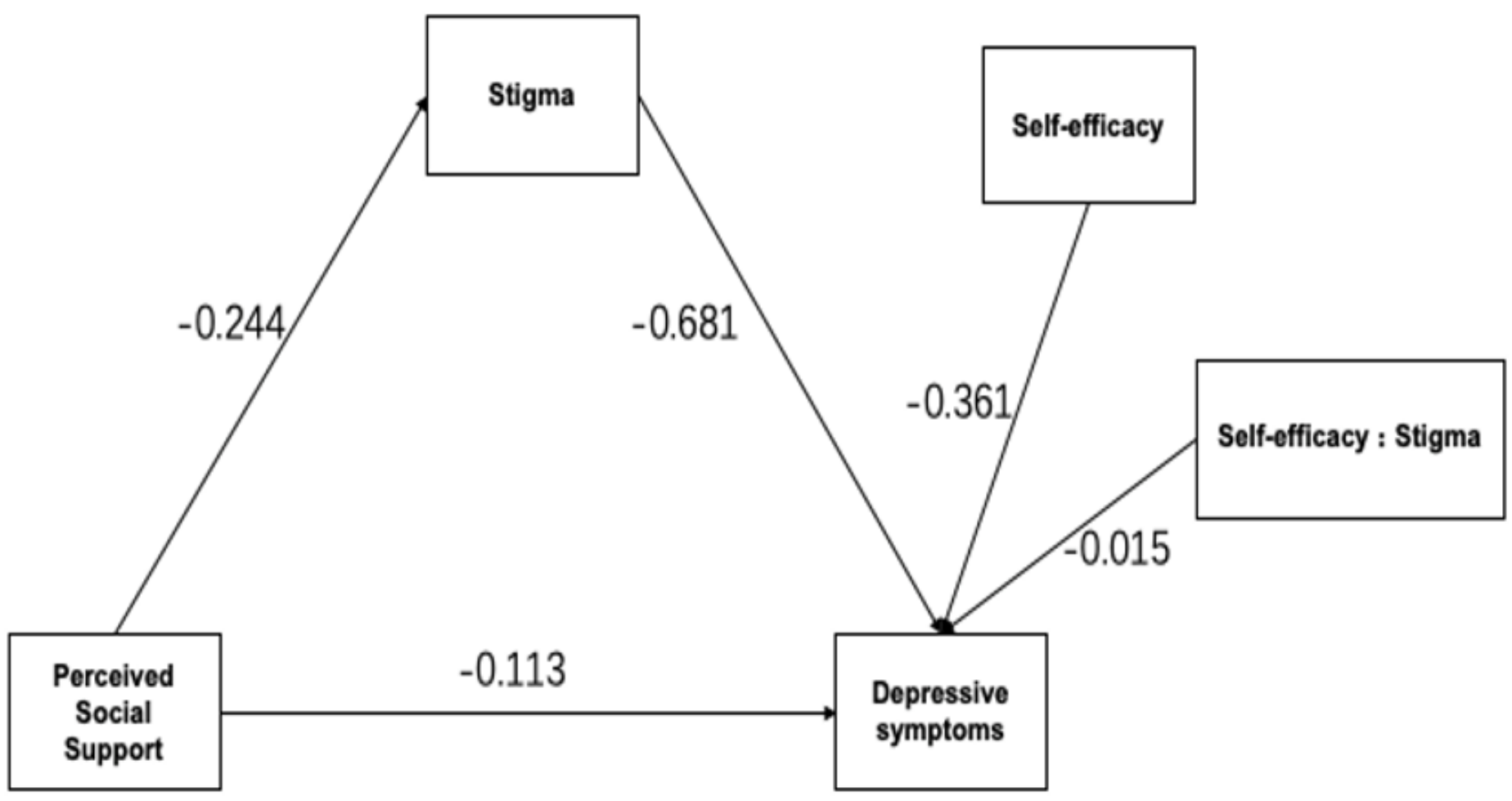


Figure 2

Unstandardized regression coefficient for the moderated mediation model.

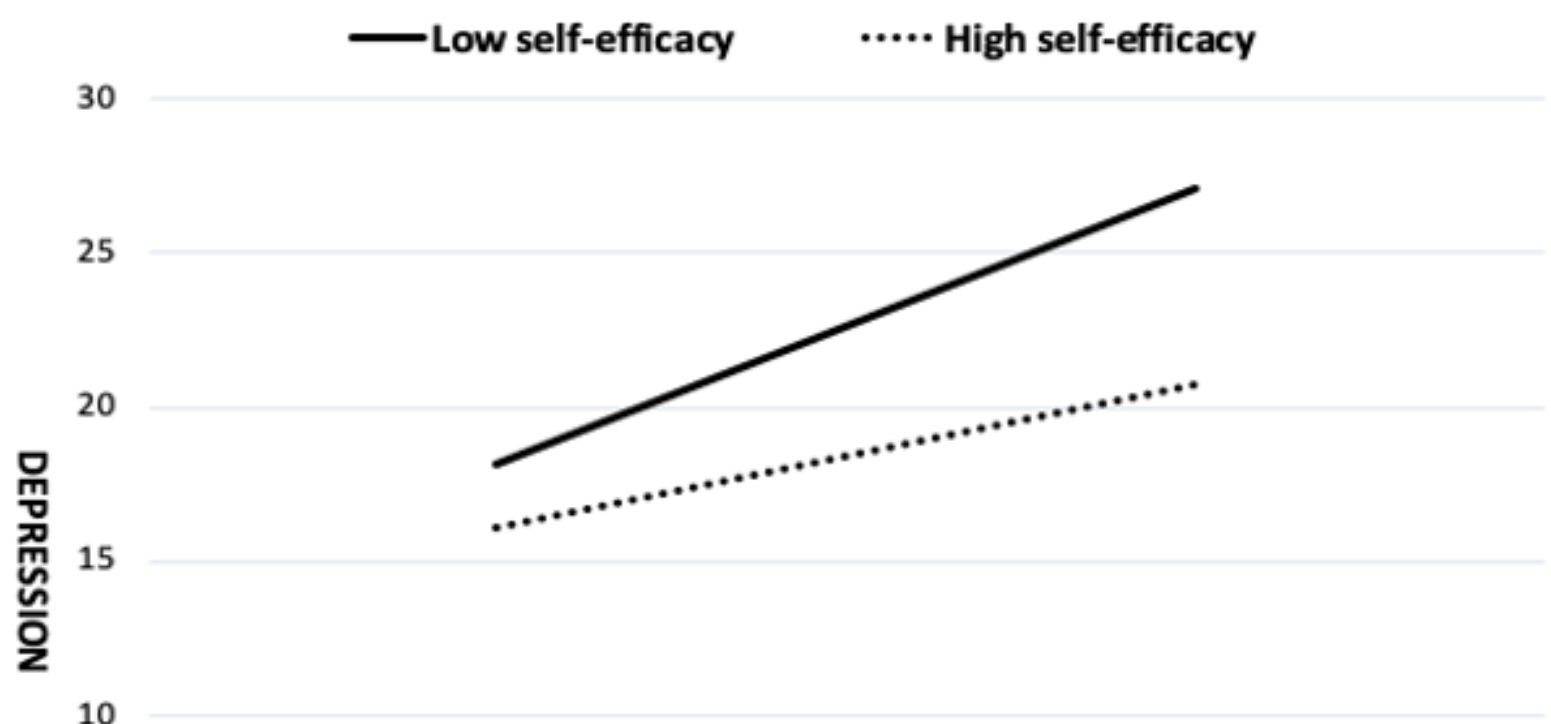

5

0

\section{Low stigma}

High stigma

Figure 3

Moderation of the effect of Stigma on depressive symptoms by self-efficacy. 